\section{(- OPEN ACCESS}

\title{
Successful repeat ECMO in a patient with AIDS and ARDS
}

\author{
Sho Horikita, ${ }^{1}$ Masamitsu Sanui, ${ }^{1}$ Yuki Fujimoto, ${ }^{1}$ Alan Kawarai Lefor ${ }^{2}$
}

\begin{abstract}
${ }^{1}$ Department of Anesthesiology and Critical Care Medicine, Jichi Medical University Saitama Medical Center, Saitama, Saitama, Japan

${ }^{2}$ Department of Surgery, Jichi Medical University, Shimotsuke, Tochigi, Japan
\end{abstract}

\section{Correspondence to}

Professor Masamitsu Sanui, msanui@mac.com

Accepted 9 June 2017

\section{CrossMark}

To cite: Horikita S, Sanui M, Fujimoto Y, et al. BMJ Case Rep Published Online First: [please include Day Month Year]. doi:10.1136/bcr-2017219870

\section{SUMMARY}

Veno-venous extracorporeal membrane oxygenation (ECMO) is being more commonly used in patients with acute respiratory distress syndrome (ARDS) due to potentially reversible illnesses. Survival from ARDS using ECMO has been reported even in patients with AIDS. However, the indications for ECMO for ARDS due to immune reconstitution inflammatory syndrome (IRIS) in patients with AIDS are unknown. A 23-year-old man with AIDS and Pneumocystis jirovecii pneumonia was admitted to the intensive care unit with severe ARDS refractory to mechanical ventilator support requiring ECMO. Although ECMO was discontinued, a second treatment with ECMO was necessary due to IRIS-associated ARDS, resulting in an excellent patient outcome. This patient's clinical course suggests two important messages. First, ECMO is a reasonable option for the treatment of patients with ARDS even in a patient with AIDS. Second, ECMO may be effective for the treatment of patients with IRIS.

\section{BACKGROUND}

Extracorporeal membrane oxygenation (ECMO) has been shown to be effective in treating patients with acute respiratory distress syndrome (ARDS), ${ }^{1}$ while the use of ECMO for an irreversible cause is considered contraindicated. Extracorporeal life support organisation (ELSO) guidelines suggest that a status predicting poor outcome despite ECMO should be considered a relative contraindication. ${ }^{2}$

Previously, the prognosis of patients with AIDS was considered poor, but a recent study showed that mortality in patients with recovered CD4(+) cell counts are not inferior compared with the general population. ${ }^{3}$ Reports from 2014 showed that patients with AIDS complicated with ARDS were successfully treated with ECMO. ${ }^{4-6}$ Therefore, the indications for ECMO in patients with AIDS should be considered on an individual basis.

Acute respiratory failure in patients with AIDS is associated with various conditions including infections by Pneumocystis jirovecii, multidrug-resistant bacteria and fungus, which were successfully treated with ECMO. ${ }^{4-6}$ However, acute respiratory failure can also result from immune reconstitution inflammatory syndrome (IRIS), a paradoxical clinical worsening after the initiation of antiretroviral therapy (ART). While ECMO seems useful as reported in these case reports, ${ }^{4-6}$ the indication of ECMO for IRIS-associated respiratory failure was not discussed. Cawcutt et al reported a patient with
AIDS, complicated with ARDS due to probable IRIS, ${ }^{4}$ where the patient required a treatment of ECMO, but was finally deceased from multiorgan failure.

We treated a patient with newly diagnosed AIDS who presented with $P$. jirovecii pneumonia $(\mathrm{PjP})$ and was subsequently complicated with probable IRIS. The patient experienced two ARDS episodes due to $\mathrm{PjP}$ and probable IRIS, both of which were successfully treated with ECMO, resulting in the patient full recovery.

\section{CASE PRESENTATION}

A 23 -year-old man presented with fever $\left(>40^{\circ} \mathrm{C}\right)$, dyspnoea and dry cough. He visited a community hospital, where he was found to be hypoxic with arterial oxygen tension $\left(\mathrm{PaO}_{2}\right)$ of $58 \mathrm{~mm} \mathrm{Hg}$ on $15 \mathrm{~L} / \mathrm{min}$ of oxygen via mask with a reservoir, requiring non-invasive positive pressure mode of ventilation (NPPV) to maintain arterial oxygen saturation. Chest X-ray and chest CT scan showed diffuse bilateral ground glass opacities. The patient received empirical antibiotics (ceftriaxone and ciprofloxacin) and methylprednisolone $1 \mathrm{~g}$ daily for 3 days with no improvement in respiratory status, and the patient was transferred to our hospital. After admission, the patient's respiratory status further deteriorated, requiring intensive care unit (ICU) admission and endotracheal intubation with ventilator support.

The following day, the diagnosis of AIDS was made with a CD 4 count of 8.5 cells/ $\mu \mathrm{L}$ and an HIV virus load of 550000 copies/mL. A PCR was positive for $P$. jirovecii in the bronchoalveolar lavage fluid. Trimethoprim/sulfamethoxazole (TMP/SMX) was initiated for the treatment of PjP. In addition, the antibacterial regimen was changed to meropenem, vancomycin, ciprofloxacin, micafungin and ganciclovir. Methylprednisolone $1 \mathrm{mg} / \mathrm{kg}$ per day was continued.

Unfortunately, he developed hypoxaemia refractory to mechanical ventilation; arterial blood gas analysis showed persistent hypoxaemia $\left(\mathrm{PaO}_{2}\right.$ of $48 \mathrm{~mm} \mathrm{Hg}$ ) on $100 \%$ fraction of inspired oxygen $\left(\mathrm{FiO}_{2}\right)$ with positive end expiratory pressure of $12 \mathrm{~cm} \mathrm{H}_{2} \mathrm{O}$ on ICU day 3 (figure 1).

A decision was made to treat the patient with venous-venous ECMO. He was subsequently initiated with circuit flow of $4.0 \mathrm{~L} / \mathrm{min}$ and sweep gas of $3.0 \mathrm{~L} / \mathrm{min}$ of oxygen $\left(\mathrm{FiO}_{2}\right.$ of $\left.100 \%\right)$. Simultaneously, ART (tenofovir, emtricitabine and raltegravir) was initiated for the treatment of AIDS. During ECMO, lung protective ventilation and 


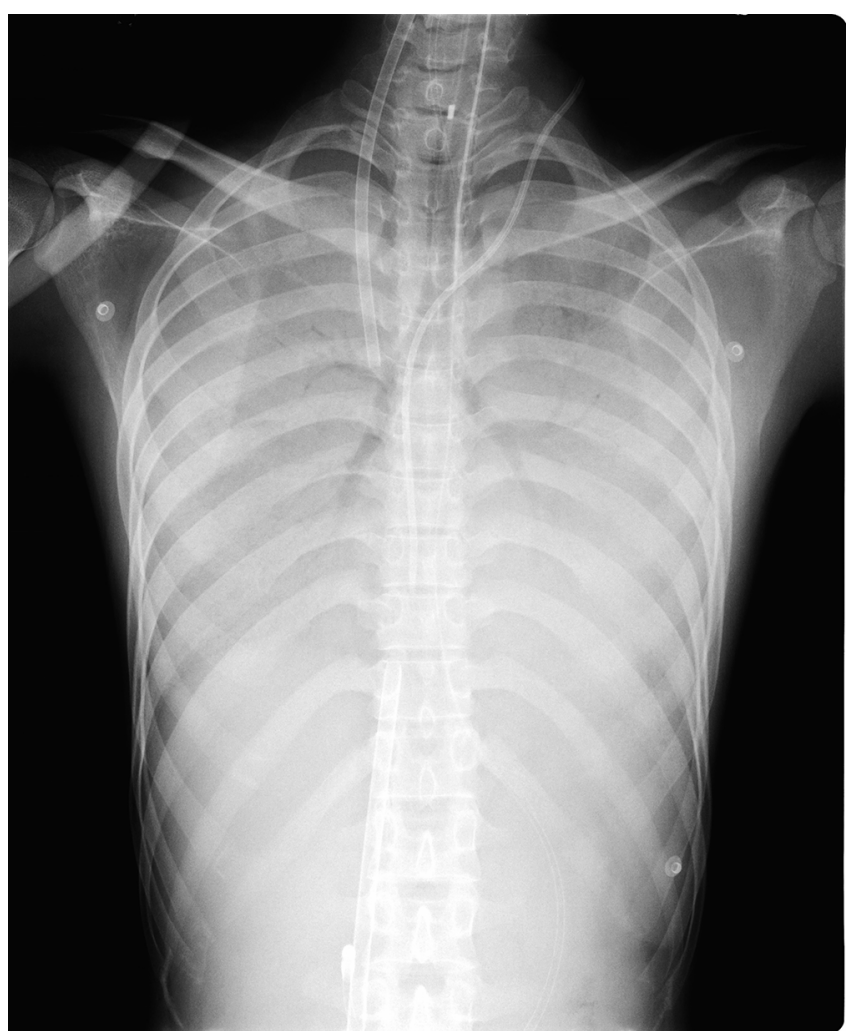

Figure 1 Chest X-ray on the day of extracorporeal membrane oxygenation initiation (intensive care unit day 3 ).

the treatment of PjP with corticosteroids and TMP/SMX were continued. Blood and sputum cultures suggested no bacterial involvement, and antibiotics (meropenem, vancomycin and ciprofloxacin) were discontinued after 2 weeks.

Gradually, chest X-ray and arterial blood gas analysis showed improvement and he was weaned from a 12-day course of ECMO support on ICU day 15 (figure 2). After removal of ECMO, the respiratory status was stable. Two days after stopping ECMO (12 days after initiating ART), however, the patient developed high fever, acute worsening hypoxia and hypercapnia refractory to increased ventilatory support, and therefore ECMO was reinstituted (figure 3).

\section{DIFFERENTIAL DIAGNOSIS}

Due to the continuation of TMP/SMX for $\mathrm{PjP}$ and a negative bacterial culture result on reinstitution of ECMO, recurrent worsening of the primary disease or a new bacterial infection was less likely. Therefore, we suspected IRIS, a paradoxical clinical worsening after the initiation of ART, as the cause of his deteriorating respiratory status.

\section{TREATMENT}

Venous-venous ECMO was reinstituted with circuit flow of $4.0 \mathrm{~L} / \mathrm{min}$ and sweep gas of $3 \mathrm{~L} / \mathrm{min}$ of oxygen $\left(\mathrm{FiO}_{2}\right.$ of $\left.100 \%\right)$. On reinstitution of ECMO, lung protective ventilation, ART (tenofovir, emtricitabine and raltegravir) for the treatment of AIDS and the treatment of PjP with corticosteroids and TMP/ SMX were continued.

\section{OUTCOME AND FOLLOW-UP}

After reinitiation of ECMO, his respiratory status gradually improved despite the development of a pneumothorax. On ICU

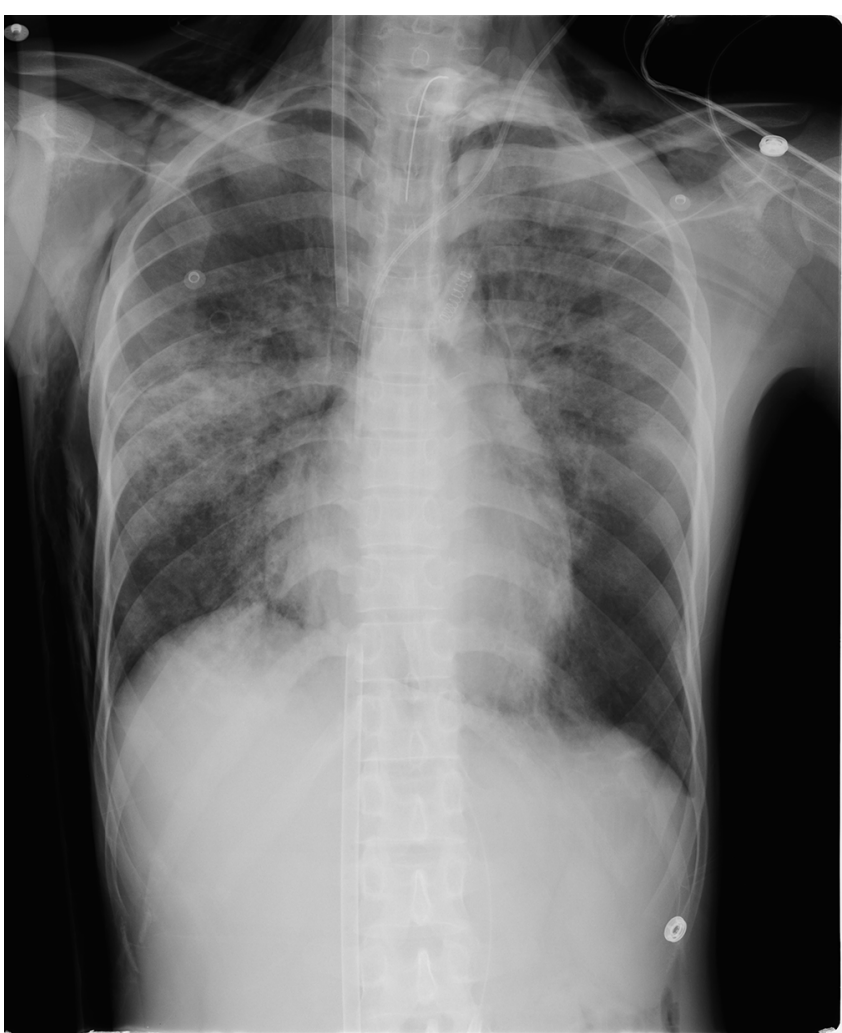

Figure 2 Chest X-ray on the day of termination of the first extracorporeal membrane oxygenation session (intensive care unit day 15).

day 30, ECMO was discontinued (14 days after reinstitution) (figure 4). Thirty days after stopping ECMO (a total of 62 days after admission), the patient was discharged home.

\section{DISCUSSION}

We treated a patient with newly diagnosed AIDS and PjP, who survived two ARDS episodes due to PjP and probable IRIS, using ECMO.

ECMO is effective in treating patients with acute respiratory failure due to potentially reversible processes, but there are no standard contraindications. ${ }^{2}$ Although ELSO guidelines suggest that there are no absolute contraindications to ECMO, a status predicting poor outcome despite ECMO should be considered a relative contraindication ${ }^{2}$ (eg, major pharmacological immunosuppression (absolute neutrophil count $\left.<0.4 \times 10^{9} / \mathrm{L}\right)$ ). Davies et al suggested that ECMO is not indicated in patients with AIDS and excluded these patients from their trial in 2009. ${ }^{1}$ However, Rodger et al reported that mortality in well-controlled patients with HIV infection, who maintained or had recovery of CD4(+) cell counts to at least $500 \mathrm{cells} / \mu \mathrm{L}$, are not inferior compared with the general population. ${ }^{3}$ Thus, the indications for ECMO in patients with AIDS should be considered on an individual basis with respect to the risks and the benefits. In fact, patients with ARDS and AIDS were successfully treated with ECMO. ${ }^{4-6}$ Similar to these patients, the current patient suggests that ECMO is a reasonable option for the treatment of ARDS, even in patients with AIDS.

IRIS is a paradoxical clinical worsening after the initiation of ART, in ART-naive patients, and presents with various symptoms depending on the characteristics and sites of the primary opportunistic infection. Low CD4 counts and high HIV-RNA counts are risk factors for the development of IRIS. ${ }^{7}$ For the 


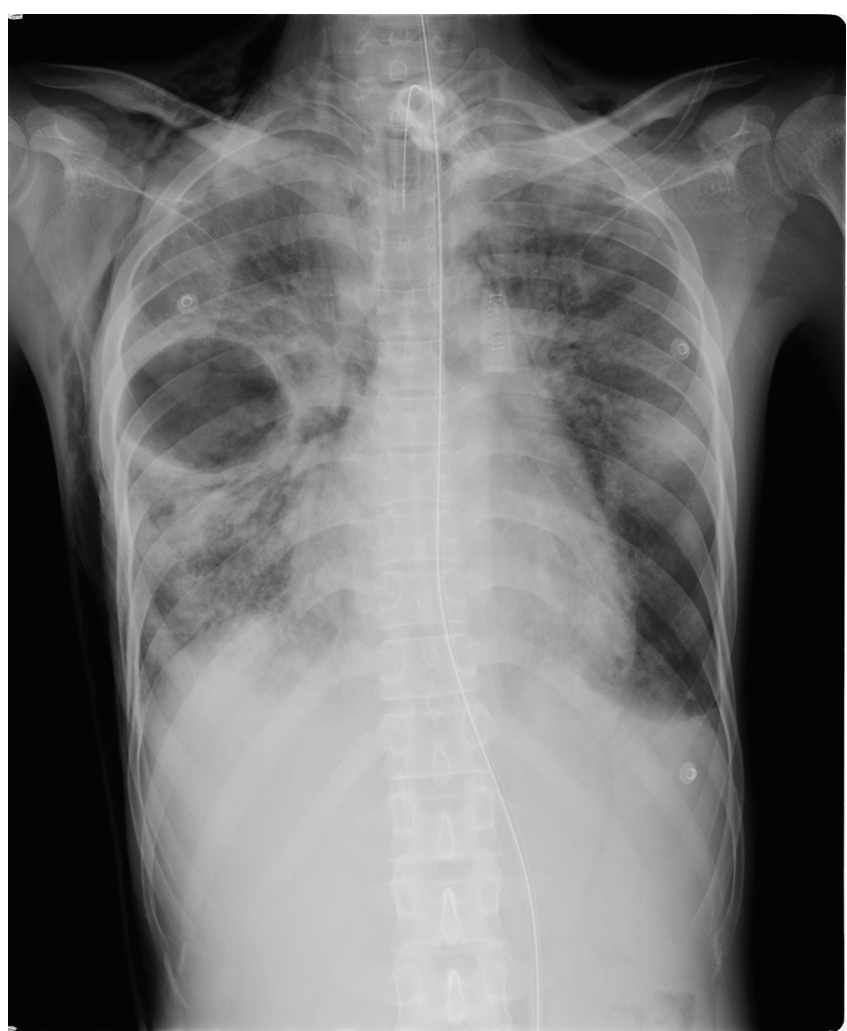

Figure 3 Chest X-ray when the patient progressed re-worsening of respiratory status and requiring the second session of extracorporeal membrane oxygenation (intensive care unit day 17).

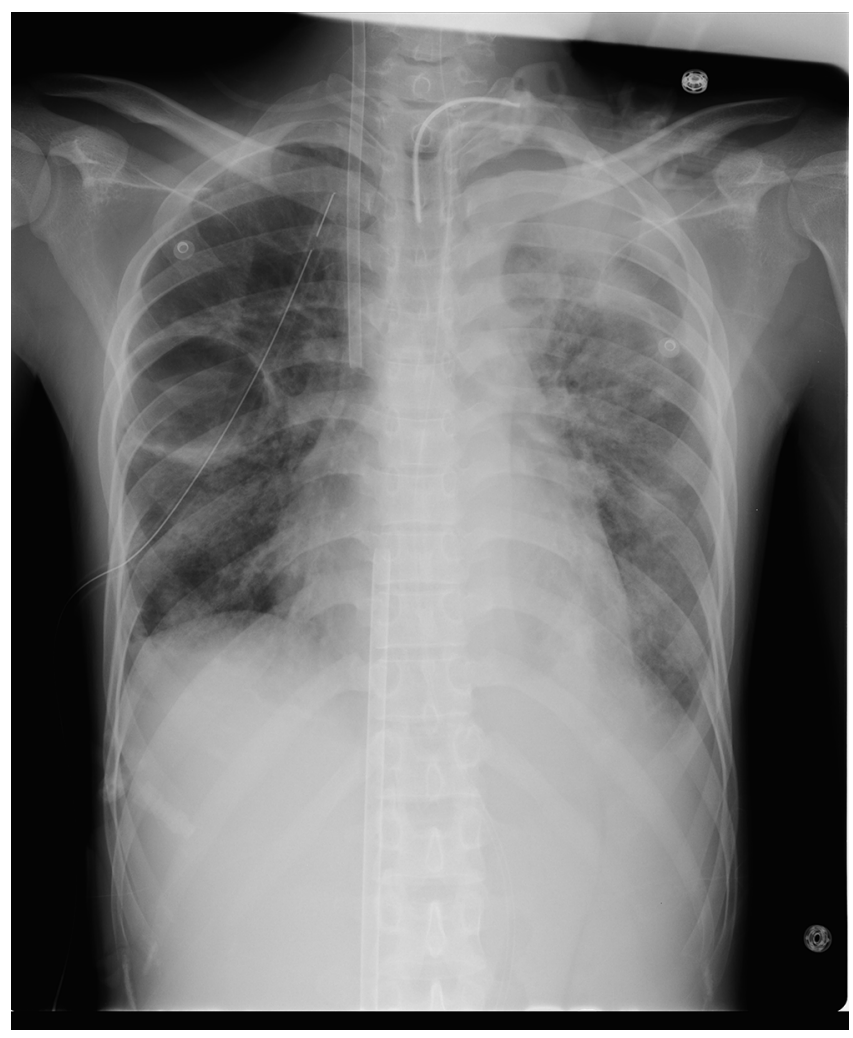

Figure 4 Chest X-ray on the day of termination of the second extracorporeal membrane oxygenation session (intensive care unit day 30). diagnosis of IRIS, the following conditions should be excluded: (1) worsening of the primary disease, (2) new bacterial infection as a complication and (3) allergic reaction to drugs. In this patient, the CD4 count was not confirmed when the respiratory status deteriorated although an increasing CD4 count is a clue to establish the diagnosis of IRIS. However, other criteria for the diagnosis of IRIS were sufficiently met by the clinical course.

It is uncertain whether ECMO is effective for IRIS-associated ARDS or not. One retrospective study suggested that patients with AIDS who developed IRIS had a higher risk of death than those who did not. ${ }^{8}$ A case with newly diagnosed AIDS, complicated by both $\mathrm{PjP}$ and probable IRIS-associated ARDS did not survive the ICU due to the multiorgan failure despite a successful separation from ECMO. ${ }^{4}$ However, IRIS is considered a self-limiting condition, depending on pathogens and organs involved. ${ }^{9}$ In the current patient, full recovery was achieved. For this reason, to use ECMO for the treatment of refractory ARDS in patients with IRIS is a reasonable option.

We used ECMO for probable IRIS, and the present patient successfully recovered from respiratory failure and was discharged home. To the best of our knowledge, this is the first report of the successful use of ECMO for IRIS-associated ARDS.

\section{Learning points}

- Extracorporeal membrane oxygenation (ECMO) may be indicated for patients with severe acute respiratory failure associated with AIDS.

- Immune reconstitution inflammatory syndrome (IRIS) is a diagnosis of exclusion in patients with acute respiratory worsening after the initiation of ART.

- ECMO may be effective in the treatment of patients with IRIS.

Acknowledgements The authors thank Drs. Hideyuki Mouri, Tetsuya Komuro, Hiroshi Koyama, Tadashi Kamio, Wataru Matsunaga, and Hirofumi Nakahari for their important contributions to the care of the patient.

Contributors SH, MS and YF contributed to the conception of the case report, acquisition of patient information, analysis and interpretation of the data. SH, MS and AKL drafted the article and revised it critically for important intellectual content. MS contributed to the care of the patient. All the authors made final approval of the version published.

Competing interests None declared.

Patient consent Obtained.

Provenance and peer review Not commissioned; externally peer reviewed.

Open Access This is an Open Access article distributed in accordance with the Creative Commons Attribution Non Commercial (CC BY-NC 4.0) license, which permits others to distribute, remix, adapt, build upon this work non-commercially, and license their derivative works on different terms, provided the original work is properly cited and the use is non-commercial. See: http://creativecommons.org/ licenses/by-nc/4.0/

(C) BMJ Publishing Group Ltd (unless otherwise stated in the text of the article) 2017. All rights reserved. No commercial use is permitted unless otherwise expressly granted.

\section{REFERENCES}

1 Davies $A$, Jones $D$, Bailey $M$, et al. Extracorporeal membrane oxygenation for 2009 influenza $A(H 1 N 1)$ aAcute respiratory distress syndrome. JAMA 2009; 302:1888-95

2 Extracorporeal Life Support Organization (ELSO). ELSO adult respiratory failure supplement to the ELSO General guidelines Version 1.3. 2013. https://www.elso.org/Portals/0/IGD/Archive/FileManager/ 989d4d4d14cusersshyerdocumentselsoguidelinesforadultrespiratoryfailure 1.3.pdf. 


\section{Novel treatment (new drug/intervention; established drug/procedure in new situation)}

3 Rodger AJ, Lodwick R, Schechter M, et al. Mortality in well controlled HIV in the continuous antiretroviral therapy arms of the SMART and ESPRIT trials compared with the general population. AIDS 2013;27:973-9.

4 Cawcutt K, Gallo De Moraes A, Lee SJ, et al. The use of ECMO in HIVIAIDS with Pneumocystis jirovecii pneumonia: a case report and review of the literature. Asaio J 2014;60:606-8.

5 De Rosa FG, Fanelli V, Corcione S, et al. Extra corporeal membrane oxygenation (ECMO) in three HIV-positive patients with acute respiratory distress syndrome. BMC Anesthesiol 2014;14:37

6 Samalavicius R, Serpytis M, Ringaitiene D, et al. Successful use of extracorporeal membrane oxygenation in a human immunodeficiency virus infected patient with severe acute respiratory distress syndrome. AIDS Res Ther 2014;11:37.
7 Murdoch DM, Venter WD, Feldman C, et al. Incidence and risk factors for the immune reconstitution inflammatory syndrome in HIV patients in South Africa: a prospective study. AIDS 2008;22:601-10.

8 Hoyo-Ulloa I, Belaunzarán-Zamudio PF, Crabtree-Ramirez B, et al. Impact of the immune reconstitution inflammatory syndrome (IRIS) on mortality and morbidity in HIV-infected patients in Mexico. Int J Infect Dis 2011. 15:e408-e414.

9 Sharma SK, Soneja M. HIV \& immune reconstitution inflammatory syndrome (IRIS). Indian J Med Res 2011;134:866-877.

Copyright 2017 BMJ Publishing Group. All rights reserved. For permission to reuse any of this content visit

http://group.bmi.com/group/rights-licensing/permissions.

BMJ Case Report Fellows may re-use this article for personal use and teaching without any further permission.

Become a Fellow of BMJ Case Reports today and you can:

- Submit as many cases as you like

- Enjoy fast sympathetic peer review and rapid publication of accepted articles

- Access all the published articles

- Re-use any of the published material for personal use and teaching without further permission

For information on Institutional Fellowships contact consortiasales@bmjgroup.com

Visit casereports.bmj.com for more articles like this and to become a Fellow 